\title{
An Experimental and Analytical Study of the Distribution of Heat in Concrete Columns
}

\author{
Manar Takla \\ Doctor, Structural Engineering Department, Faculty of civil Engineering, \\ AL- Wataniya Private University, Hama, Syria \\ Ihssan Tarsha \\ Professor, Structural Engineering Department, Faculty of civil Engineering, \\ AL- Wataniya Private University, Hama, Syria
}

\begin{abstract}
Fire is one of the most devastating disasters that have caused human damage, prompting researchers to conduct numerous studies on the behavior of fire-prone elements and take action to minimize damage. With the development of computer simulation theories, it is possible to study the behavior of structures under the influence of different loads (static, dynamic, thermal ... etc), and this leads to saving time, effort and money cost instead of performing laboratory experiments. Thermal loads are considered one of the most dangerous loads to which concrete structures are exposed. Hence it is very important to know the thermal distribution in the cross section of the element exposed to high temperature. Whereas, by knowing the thermal distribution, the designed load and the expected failure load of the structural element can be calculated and thus take the necessary measures to reduce the fire risk as much as possible. In this research, an experimental and analytical study was conducted on models of reinforced concrete columns, where thermocouple were used in different places to monitor the temperature at the specified points, The experimental thermal distribution was compared with the analytical results of the ANSYS Workbench program. The analytical results showed a great accuracy compared to the experimental results. Consequently, an analytical model was simulated to simulate the experimental, through which it is possible to know the thermal distribution of the model.
\end{abstract}

Keywords: thermal distribution, thermal analysis, thermocouple, ANSYS Workbench.

DOI: $10.7176 / \mathrm{CER} / 13-1-01$

Publication date: January $31^{\text {st }} 2021$

\section{1- Introduction}

Reinforced concrete is the basic material for construction, which is used in the installation of most engineering facilities around the world, the exposure of reinforced concrete structures to fire, is one of the most dangers challenges that lead to great destruction and failure the structural in addition to loss of life. The first scientific attempts to test the resistance of structures elements to fire date back to the beginning of the twentieth century, and then developed continuously, until they resulted in the development of standard specifications for testing materials and elements alike [1].

With the development of computer simulation theories to study the behavior of elements and structures under the influence of different loads (static, dynamic, thermal, etc.), it became possible to study the behavior of concrete columns under the influence of axial loads and non-axial, and to study the effect of fire and high temperature on these columns.

Using the Finite Element Theory, we can model the behavior of concrete in a nonlinear manner, taking into account the causes of failures such as the formation of cracks or the crushing of concrete, or the yielding of steel reinforcement.

It is also possible to merge different types of analysis, such as structural analysis (static and dynamic) with thermal analysis and obtain results corresponding to the results that can be obtained through laboratory experiments with acceptable accuracy.

In this paper, an experimental study (using thermal thermocouples) and an analytical (using the ANSYS Workbench program) was conducted to determine the thermal distribution in concrete columns when exposed to heat according to an electric furnace curve for a period of two hours.

\section{2- Aim and importance of research:}

Since columns are an important structural component, studying the impact of fire on them is an important subject.Therefore, in this research, an experimental, analytical study was made to determine the thermal distribution of the columns, and a comparison between them was made, to know the accuracy of the analytical model.

Thus, arriving an analytical model, that simulates reality, through which it can help the designer engineer to predict the value of the failure load of the structural elements exposed to fire. 
For this purpose, 3 reinforced concrete columns with dimensions ( $15 \times 15 \times 40) \mathrm{cm}$ tested experimentally, as the samples were subjected to a temperature increase over time up to (120 minutes), where the temperature of the furnace reached $680^{\circ} \mathrm{C}$, while the surface temperature of the concrete reached $581^{\circ} \mathrm{C}$ at same time.

\section{3- Experimental work : [2], [3]}

A concrete mixture was prepared for three samples of the columns where the mixture was designed to determine the ideal percentages of the materials used in its composition to obtain concrete with good mechanical resistance and suitable workability commensurate with the importance and type of the structure to be implemented. All materials needed to complete the experimental work, were tested. Where experiments were conducted: sieve analysis, specific weight and volumetric, sand equivalent, determine the coefficient of abrasion (LA), and the degree of impregnation of gravel materials $\left(\% \mathrm{~W}_{\mathrm{asp}}\right)$. For use in designing the concrete mixture, according to the requirements of ASTM E11-16. Conducting the tensile experiment for reinforce steel samples was also conducted according to ASTM E8-13, and we show in Table (1) the results of the tests:

Table (1) test results:

\begin{tabular}{|c|c|c|c|c|c|c|}
\hline Material & $\begin{array}{c}\text { Sieve } \\
\text { gradient }\end{array}$ & $\begin{array}{c}\text { Specific } \\
\text { volumetric }\end{array}$ & $\begin{array}{c}\text { Specific } \\
\text { weight }\end{array}$ & $\begin{array}{c}\text { Sand } \\
\text { equivalent }\end{array}$ & $\begin{array}{l}\text { Coefficient } \\
\text { of Abrasion }\end{array}$ & $\begin{array}{c}\text { Degree of } \\
\text { impregnation }\end{array}$ \\
\hline & $\mathrm{d}(\mathrm{mm})$ & $\gamma\left(\mathrm{Kg} / \mathrm{m}^{3}\right)$ & G & $\%$ E. S & \%L.A & $\% \mathbf{W}_{\text {asp }}$ \\
\hline Coarse aggregate & $19-4.75$ & 1360 & 2.70 & - & 21 & 1.5 \\
\hline Fine aggregate & $9.5-2.36$ & 1490 & 2.68 & - & - & - \\
\hline Coarse sand & $4.75-0$ & 1580 & 2.65 & 88 & - & - \\
\hline Fine sand & $1.2-0$ & 1540 & 2.55 & 64 & - & - \\
\hline
\end{tabular}

In order to design the concrete mixture, the schematic method (Fuller-Thompson) was adopted in determining the proportions the materials of gravel as in figure (1).

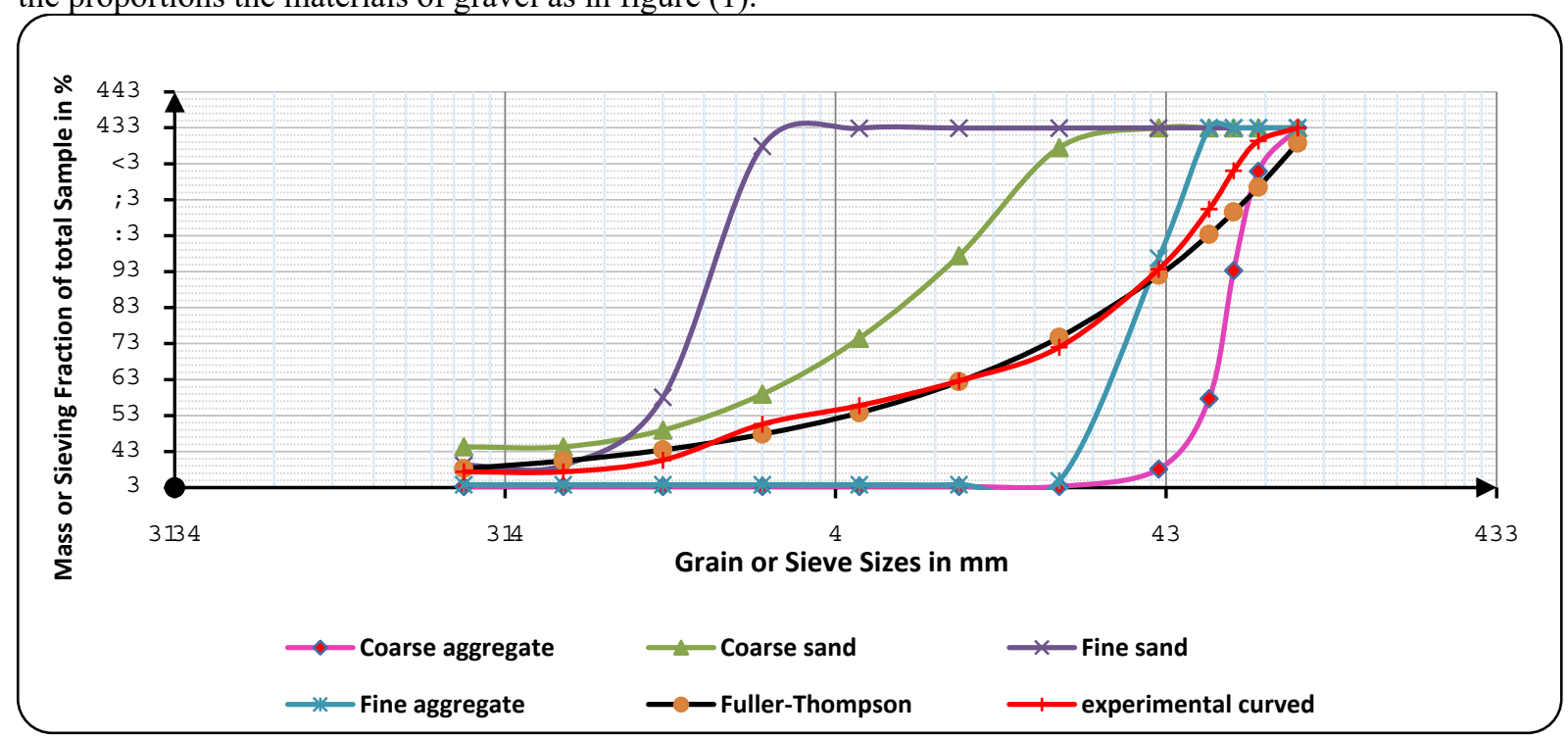

Figure 1: Granular analysis curves for the used aggregate material

The compressive strength of concrete was determined according to the American specifications ASTM C3972 , where the experiment was performed on 3 regular cylindrical samples with dimensions $(15 \times 30 \mathrm{~cm})$ using the compression test machine located in the building materials laboratory at the Faculty of Civil Engineering at AlBaath University as shown in the figure (2).

The tensile test of reinforcing steel samples was also carried out, according to the American specification ASTM E8-13, where 3 samples of each type of steel reinforcement were tested in the building materials laboratory at the Faculty of Civil Engineering at Al-Baath University as shown in figure (3), and the table (2) shows the average value of those experiments' results. 

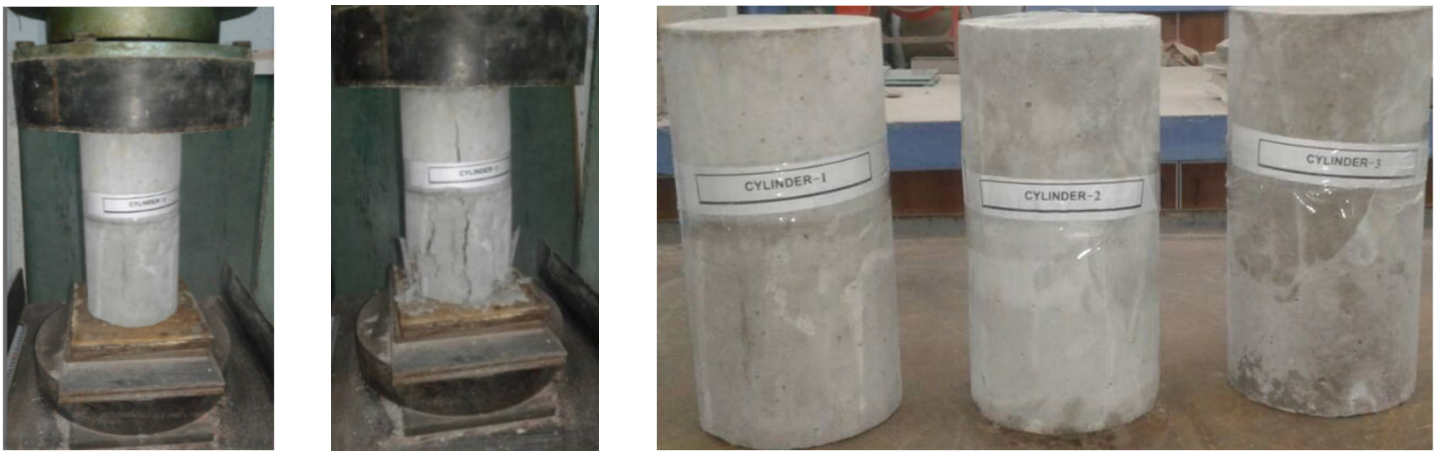

Figure (2): compressive strength of concrete for cylinder regular
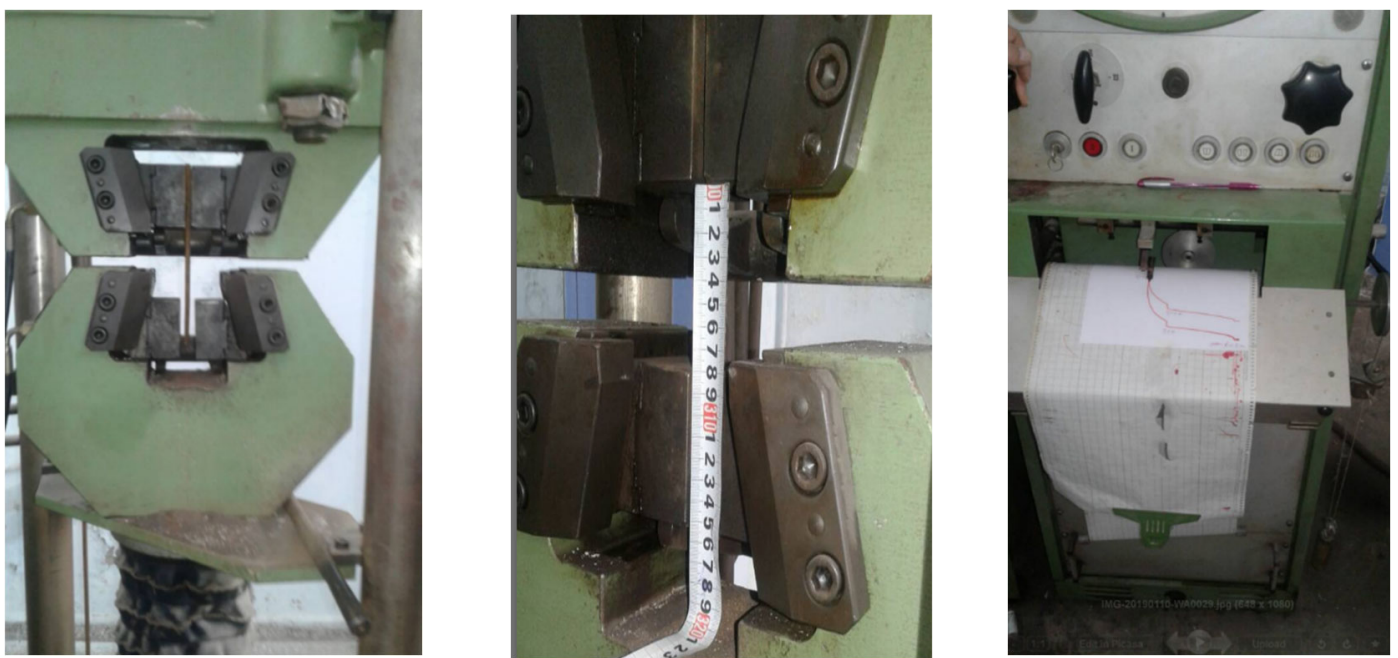

Figure 3: Tensile testing of steel reinforcement samples

Table (2): Average values of the regular cylinders test on axial compressive at 28 days of age and tensile tests for reinforcement samples

\begin{tabular}{|l|l|}
\hline Axial compressive test to determine cylindrical resistance to concrete & $\mathbf{f}_{\mathrm{cm}}^{\prime}=\mathbf{2 1 . 5} \mathrm{MPa}$ \\
\hline Tensile test for longitudinal reinforcement $(12 \mathrm{~mm})$ to determine yield stress & $=454 \mathrm{MPaf}_{\mathrm{y}}$ \\
\hline Tensile test for stirrups reinforcement $(8 \mathrm{~mm})$ to determine yield stress & $=430 \mathrm{MPaf}_{\mathrm{y}}$ \\
\hline
\end{tabular}

To measure the temperature, thermocouples type $\mathrm{k}$ were used in three places of the sample to measure the temperature with time. As a thermocouple was placed at the longitudinal reinforcement (1), a thermocouple in the middle of the sample to know the temperature in the concrete (2), and the last one to measure the temperature of the stirrups reinforcement with time (3), as shown in figure (4). The experimental thermal distribution will be compared with the analytical results using ANSYS Workbench program. Figures $(5,6$, and 7$)$ illustrate the experimental work stages for placing the sensors.
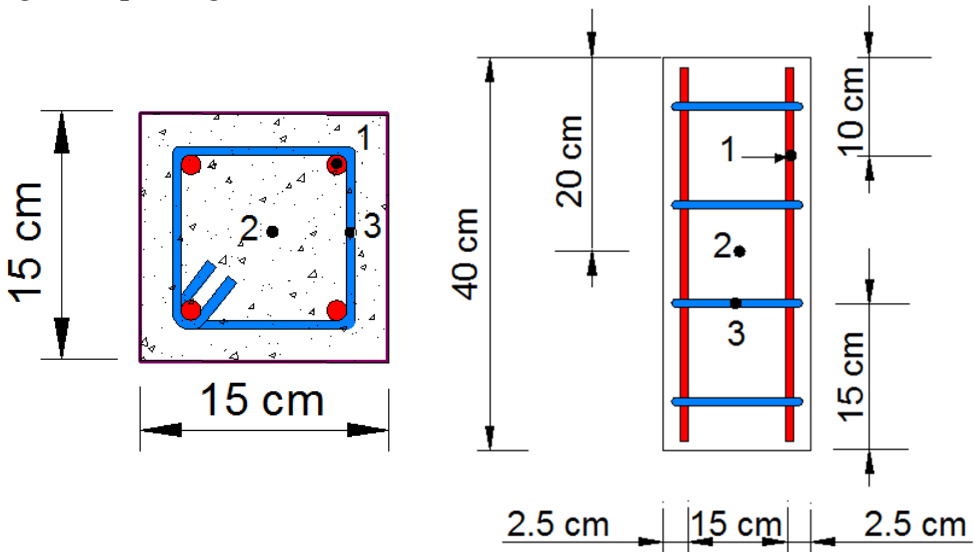

Figure (4): Preparing the concrete mixture 

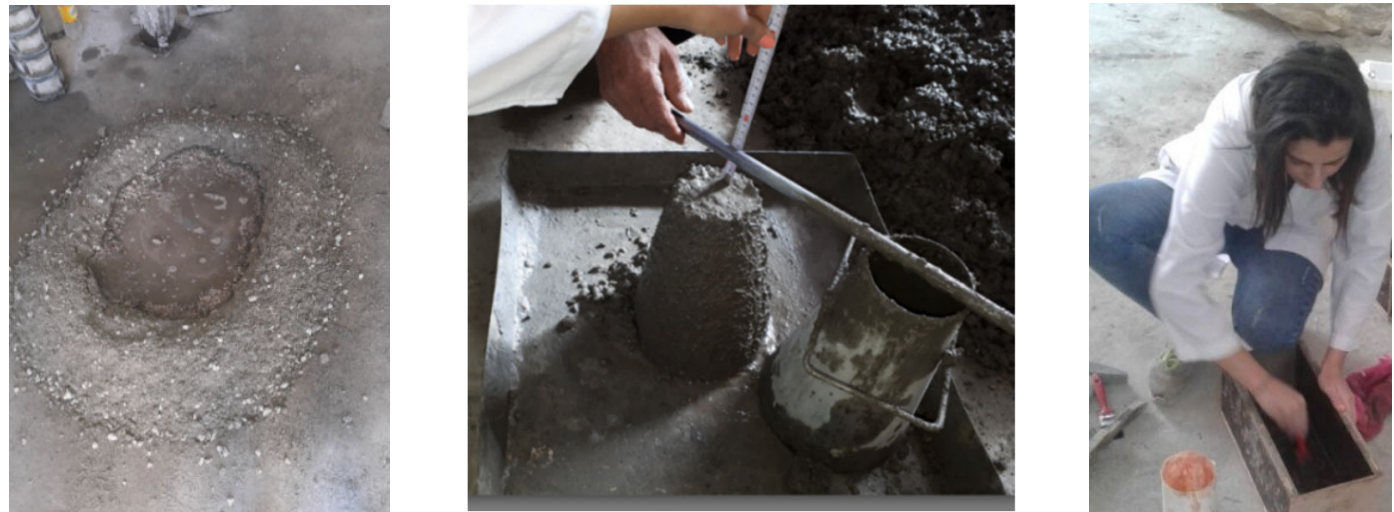

Figure 5: A longitudinal and cross-section of the column showing The points where the thermocouples were placed
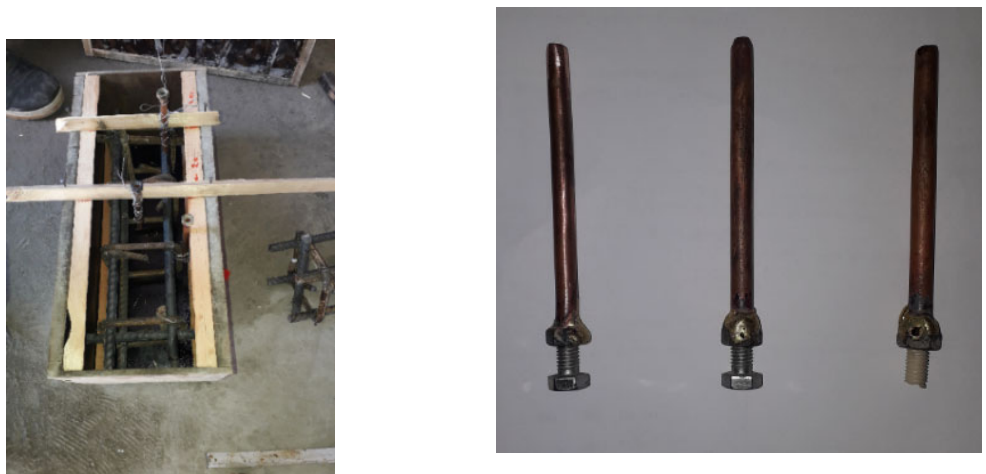

Figure 6: Place of tubes for thermocouples in the columns before casting
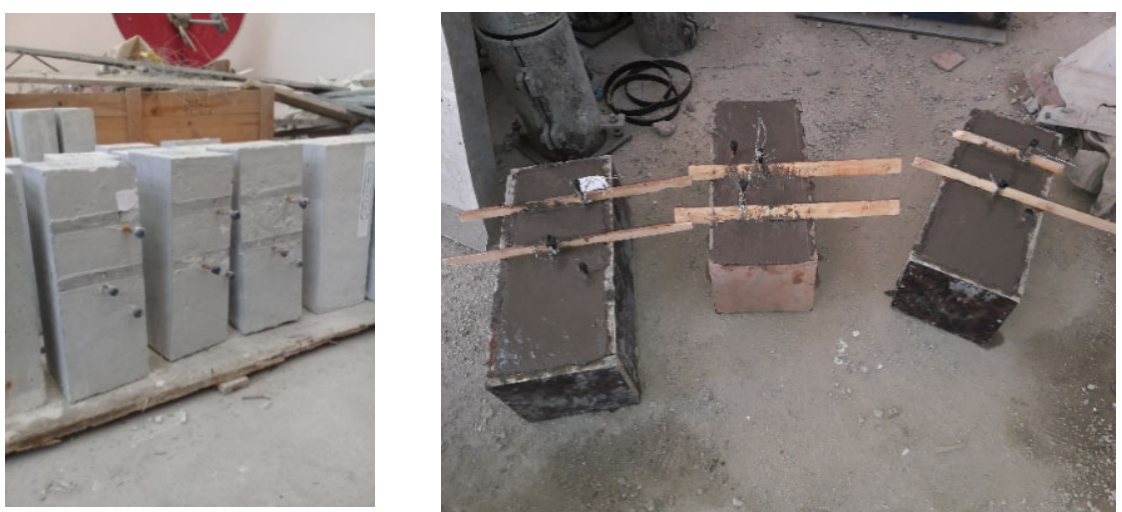

Figure 7: Place of tubes for thermocouples in the columns before casting

\section{4- Determination of the thermal conductivity coefficient [2], [4], [5]}

We call heat transfer as conduction; if there is a difference in temperature in a medium, (it may be solid or fluid). Therefore conduction is considered a transfer of energy, from particles (particles of matter), that increase their energy (those with higher energy), to neighboring particles that have less energy (those with less energy), and that when these particles interact with each other.

Heat transfer has direction as well as quantity, and the rate of heat transfer by conducting in one direction is directly proportional to the temperature gradient (which is the amount of change in temperature, for each amount of length in that direction). Heat transfer with conduction in a given object, is a time-related three-dimensional process, which means that $\mathrm{T}=\mathrm{T}(\mathrm{x}, \mathrm{y}, \mathrm{z})$.

The thermal conductivity coefficient $(\mathrm{k})$ was measured, which is a measure of the material's ability to transfer heat through it by conduction, is measured by $(\mathrm{W} / \mathrm{m} . \mathrm{k})$ or $\left(\mathrm{W} / \mathrm{m} .{ }^{\circ} \mathrm{C}\right)$, depending on the theory of the Fourier, who formulated the heat flow equation that shown in the relationship (1).

$$
q_{x}=-k \frac{d T}{d x}
$$

Where : 
$\mathrm{k}$ :Thermal conductivity coefficient $(\mathrm{W} / \mathrm{m} . \mathrm{k})$ or $\left(\mathrm{W} / \mathrm{m} .{ }^{\circ} \mathrm{C}\right)$

$\frac{\mathrm{dT}}{\mathrm{dx}}$ : The temperature gradient, which is the slope of the temperature curve.

* The negative sign was added to make the heat transfer in the $\mathrm{x}$-direction positive.

To measure the thermal conductivity coefficient of concrete $(\mathrm{k})$, three cubic concrete samples with dimensions $(15 \times 15 \times 15) \mathrm{cm}$ were cast figure (8), thermal conductivity-measuring device was used, which was manufactured in the Faculty of Mechanical Engineering at Al-Baath University [5] as shown figure (9). The experiment was conducted according to the specification of ASTM C177, and the results are shown in table (3).

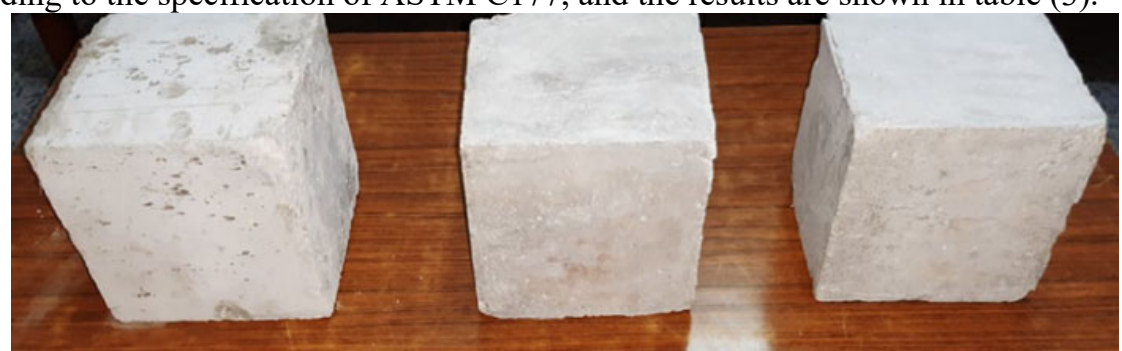

Figure (8): The tested concrete samples with dimensions $(15 \times 15 \times 15) \mathrm{cm}$ To measure the thermal conductivity coefficient

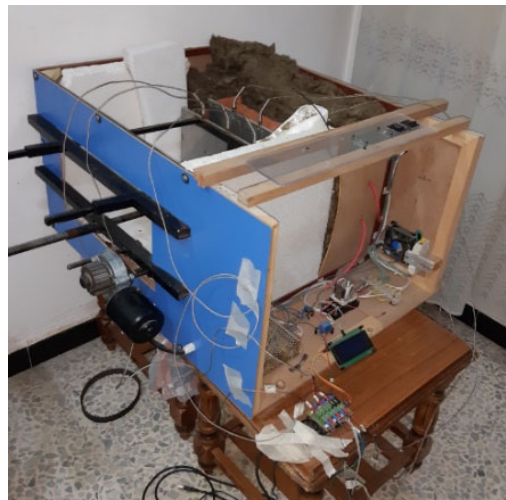

Figure 9: Device of thermal conductivity coefficient [5]

Table 3: Thermal conductivity coefficient of concrete

\begin{tabular}{|c|c|}
\hline Material & Thermal conductivity coefficient $\left(\mathrm{W} / \mathrm{m} .{ }^{\circ} \mathrm{C}\right)$ \\
\hline Concrete & 1.72 \\
\hline
\end{tabular}

\section{5- Experimental testing of samples:}

The experiment was carried out in the laboratory of plumbing and smelting at the Faculty of Mechanical Engineering at Al-Baath University, where an electric furnace was used with electromagnetic coil, and an electronic panel showing the temperature of the furnace as shown in figure (10).

The sample was placed in the furnace, where it was exposed to high temperatures from the four sides, and by using the laser thermometer shown in figure (11), the temperatures were recorded on the surface of the sample with time. A curve was drawn, that expresses the temperature increase with time for the furnace and the surface of the sample, as well as shown in figure (12).

As for figures (13-14), the relationship between the rise temperature for the furnace and the surface of the sample with time, has been expressed according to a relationship that was deduced using the Orign2019 program [6]. This equation will be depended on, when conducting thermal analysis using ANSYS Workbench program.

As for the thermocouples, they were protected from direct exposure to heat by using wire heat shield, and they were reached to Data Logger device, that measures the temperature with time, and took a reading every 1 second. Figure (15) shows the Data Logger and wire heat shield in addition to the thermocouples. 

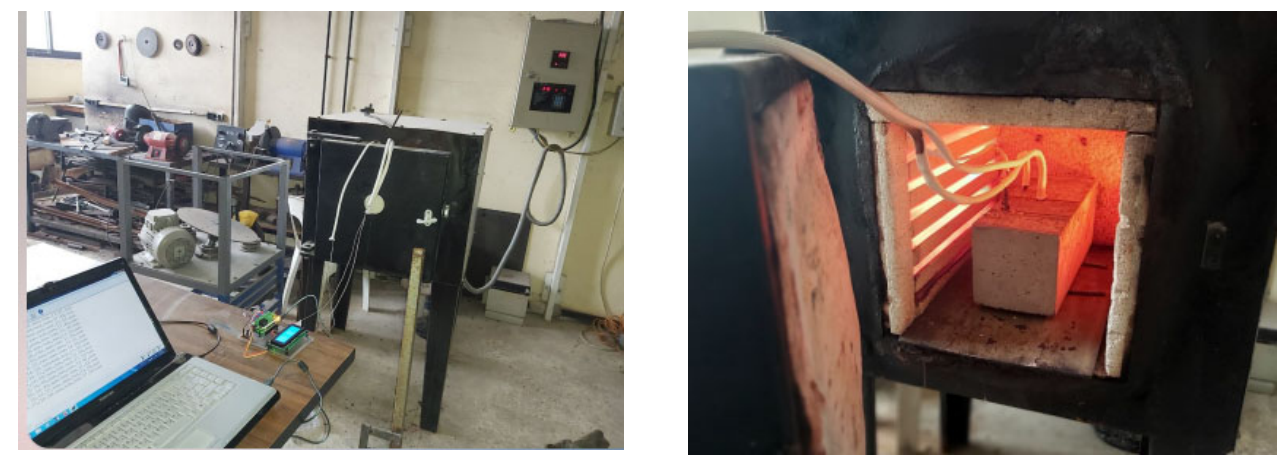

Figure (10): site of the sample in the electric furnace and the method for Connecting the thermocouples to the Data Logger device
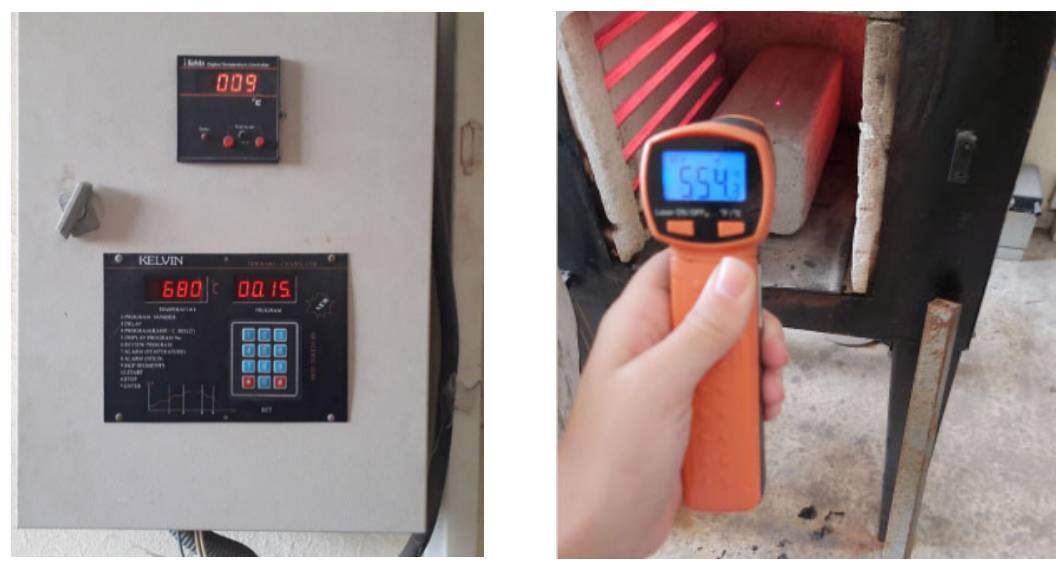

Figure (11): A laser thermometer to determine the temperature on the sample surface and the electronic panel that shows the electric furnace temperature

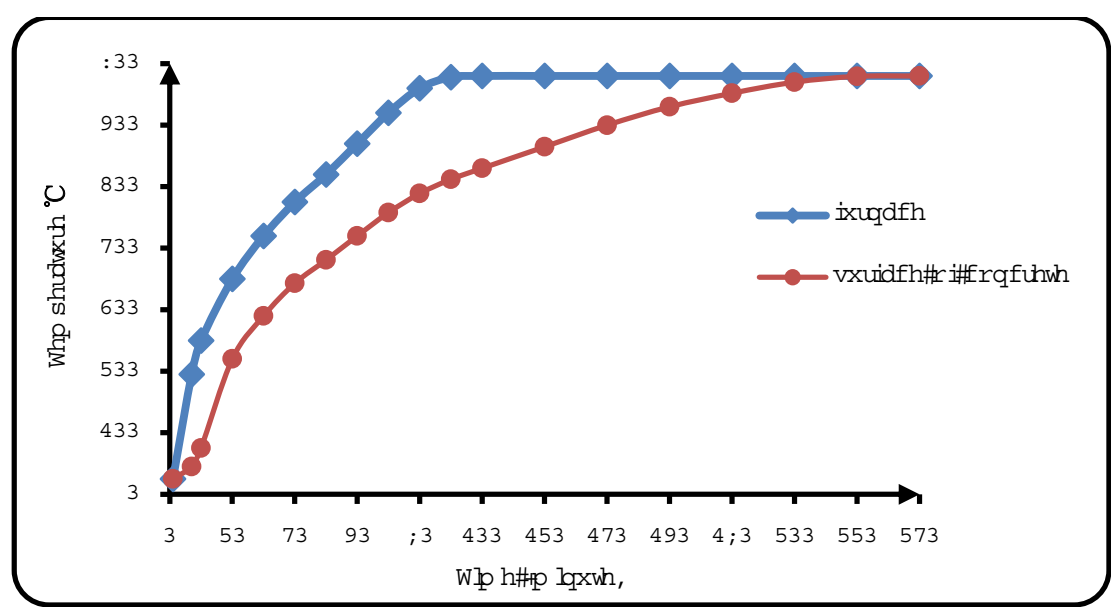

Figure (12): Temperature curve of the furnace and the concrete surface experimentally 


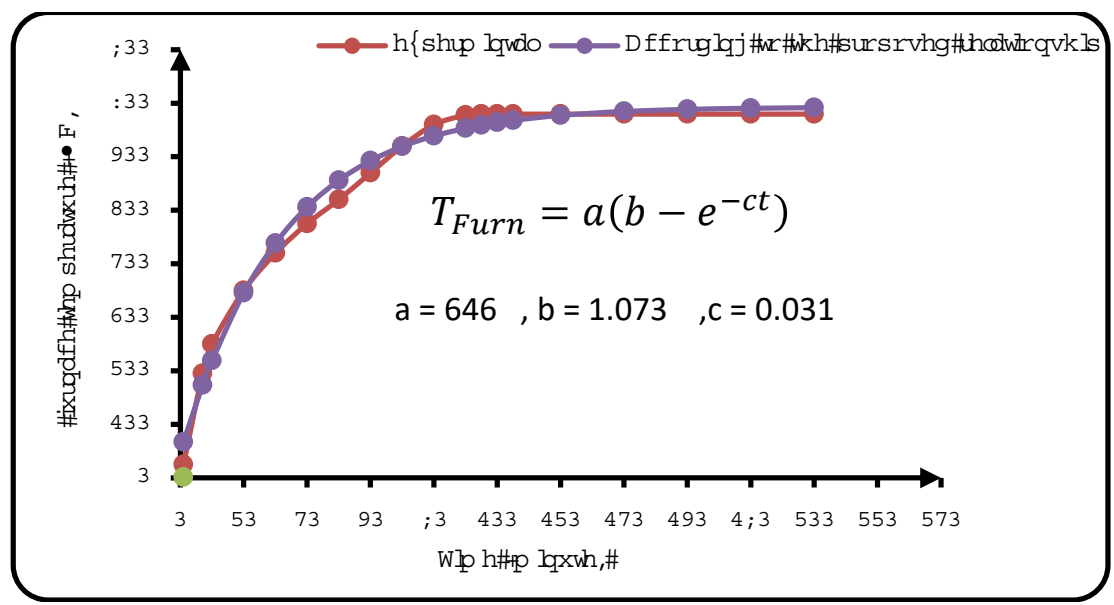

Figure (13): change the temperature of the furnace with time experimentally and according to the suggested relationship

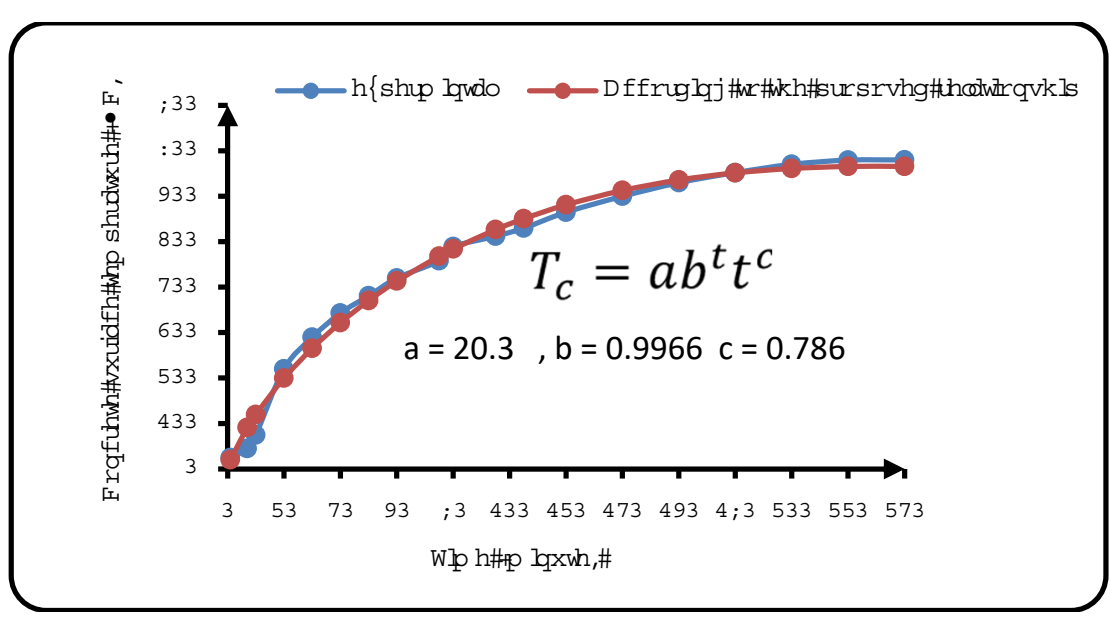

Figure (14): change the temperature of the concrete surface with time experimentally and according to the suggested relationship

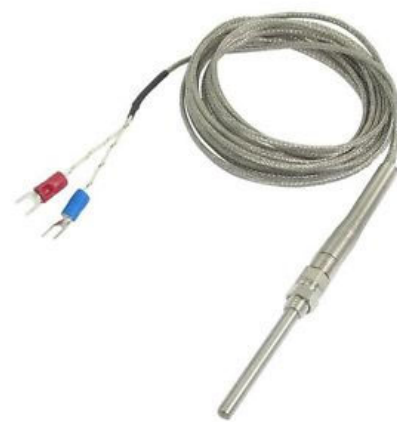

Thermocouple Type K

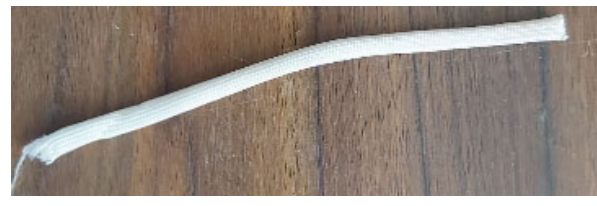

wire heat shield

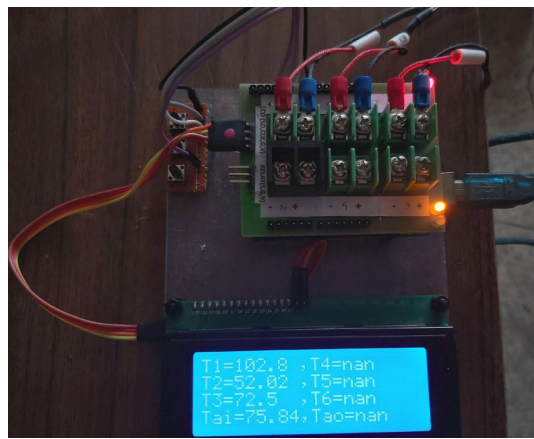

Data Logger

Figure (15): The tools used in the test

\section{6- Thermal analysis using ANSYS Workbench Program [7], [8]}

To conduct thermal analysis, the thermal properties of the materials must be determined and appropriate elements used, to characterize the structural element. Table (4) shows the thermal properties and elements that have been applied in thermal analysis, using the ANSYS Workbench finite element program [9]. Figure (16) shows the modeling of the concrete column. 
Table (4): Thermal properties, elements used

\begin{tabular}{|c|c|c|c|}
\hline \multirow{4}{*}{ Concrete } & \multirow{4}{*}{ Solid70 } & Density $\left[\mathrm{Kg} / \mathrm{m}^{3}\right]$ & 2408 \\
\hline & & Specific heat $[\mathrm{J}] /[\mathrm{Kg}] .[\mathrm{K}]$ & 1000 \\
\hline & & $\begin{array}{l}\text { Coefficient of thermal conductivity [W]/ } \\
{[\mathrm{m}] .[\mathrm{K}]}\end{array}$ & 1,72 \\
\hline & & Thermal expansion & $1 \mathrm{e}-5$ \\
\hline \multirow{4}{*}{ Reinforcement steel } & \multirow{4}{*}{ Link33 } & Density $\left[\mathrm{Kg} / \mathrm{m}^{3}\right]$ & 7850 \\
\hline & & Specific heat $[\mathrm{J}] /[\mathrm{Kg}] .[\mathrm{K}]$ & 600 \\
\hline & & $\begin{array}{l}\text { Coefficient of thermal conductivity }[\mathrm{W}] / \\
{[\mathrm{m}] .[\mathrm{K}]}\end{array}$ & 45 \\
\hline & & Thermal expansion & $1,3 e-5$ \\
\hline
\end{tabular}
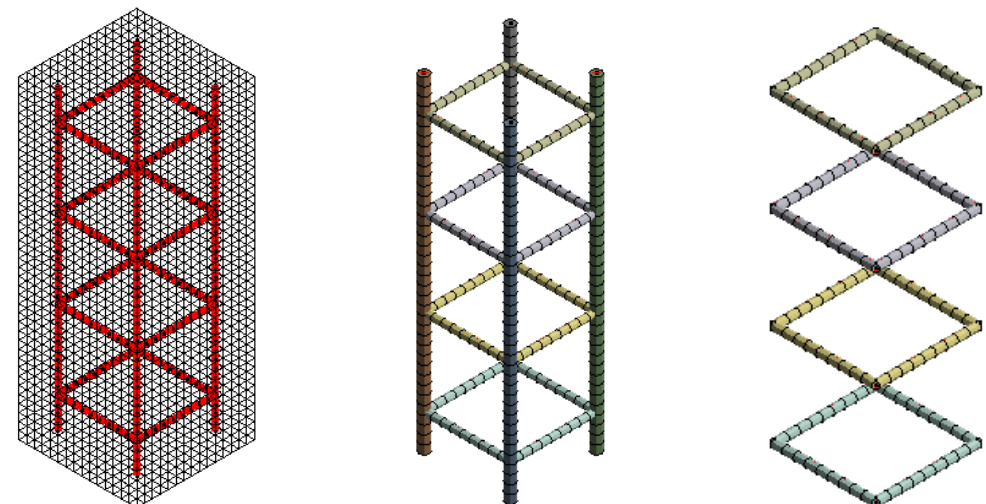

Figure 16: Modeling the concrete column and meshing

\section{7- Experimental and analytical results:}

Table (5) shows the average analytical and experimental results of the measured temperatures at the thermocouples $(1,2,3)$, which represent (longitudinal reinforcement, concrete, and stirrups reinforcement), where we note that the largest difference in the results is $(3.8 \%)$.

Table (5): Thermal analysis and experimental results using thermocouples

\begin{tabular}{|c|c|c|c|c|c|c|c|c|c|c|}
\hline $\begin{array}{c}\text { thermocouple } \\
\text { number }\end{array}$ & Time (minute) & 4 & 12 & 24 & 35 & 50 & 73 & 95 & 112 & 120 \\
\hline \multirow{2}{*}{1} & Experimentally & 27.2 & 63.4 & 133.5 & 212 & 291.3 & 394.3 & 475 & 519 & 531 \\
\hline & Analytically & 21.3 & 62.5 & 136.9 & 208 & 285.3 & 388.2 & 467 & 516 & 535 \\
\hline \multirow{2}{*}{2} & Experimentally & 17.7 & 23.8 & 59.5 & 107.3 & 178.6 & 284.3 & 378.2 & 426 & 460 \\
\hline & Analytically & 20 & 22 & 60.3 & 105.8 & 171 & 272.8 & 364.3 & 428 & 455.5 \\
\hline \multirow{2}{*}{3} & Experimentally & 21 & 56 & 126.8 & 193.4 & 274.9 & 383.7 & 463.6 & 511.5 & 520.7 \\
\hline & Analytically & 18 & 64 & 135 & 199.3 & 277.2 & 379.5 & 458.3 & 507.3 & 527.1 \\
\hline
\end{tabular}

Figures $(17,18$, and 19) show the thermal response to the three points that represent the locations of the thermocouples, experimentally and analytically. A relationship has also been established to describe the temperature rise of the studied points according to time. Figure (20) shows the thermal response of the three points analytically. 

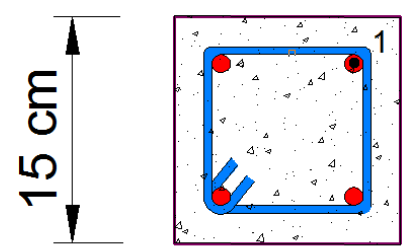

$$
\begin{aligned}
& 988-1 \\
& 788
\end{aligned} \quad T_{\text {Point }}=\left(\boldsymbol{a} \times \boldsymbol{b}^{\boldsymbol{t}} \times \boldsymbol{t}^{c}\right)
$$
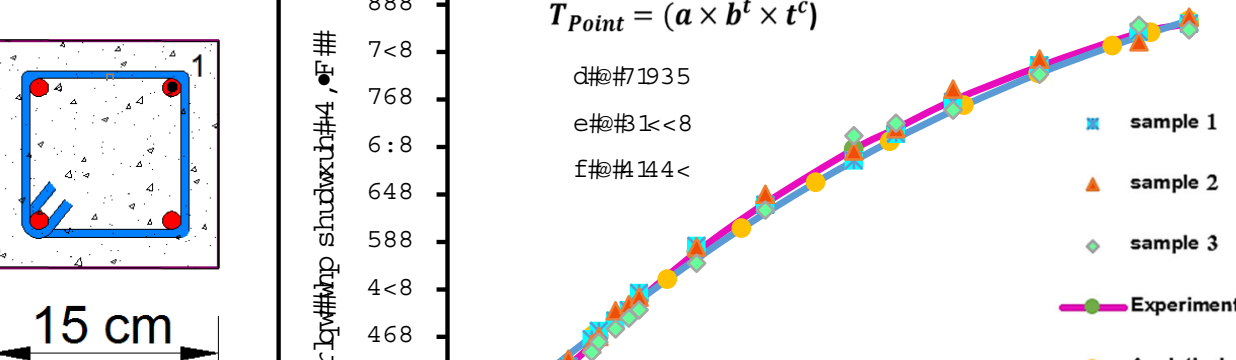

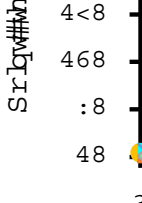

$=$ Experimental average

$=$ Analytical

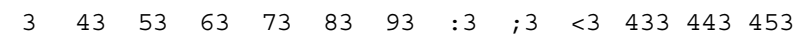

Wlp h\#p lqxwh,

Figure (17): The thermal response to point 1 experimentally (for three samples) and analytically
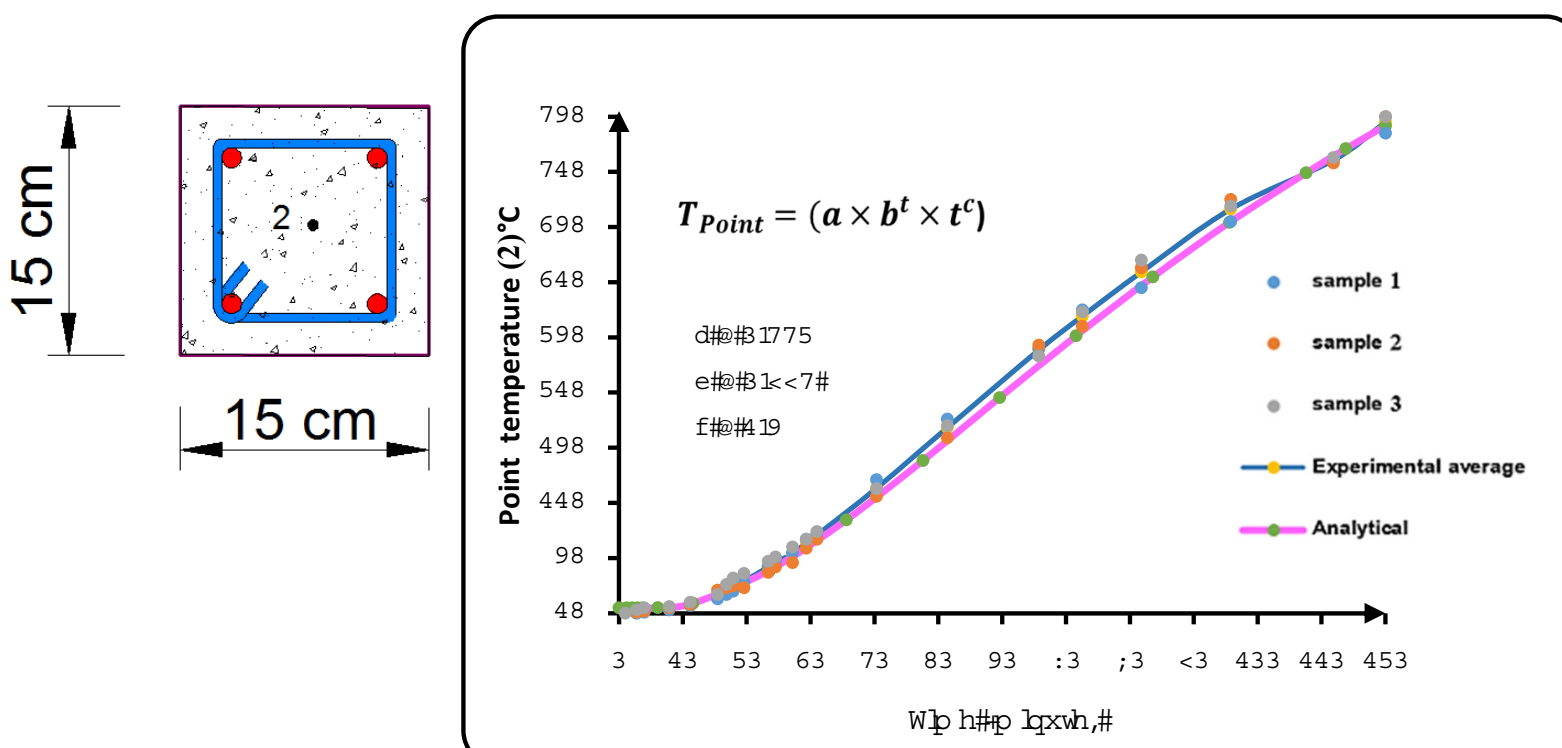

Figure (18): The thermal response to point 2 experimentally (for three samples) and analytically 

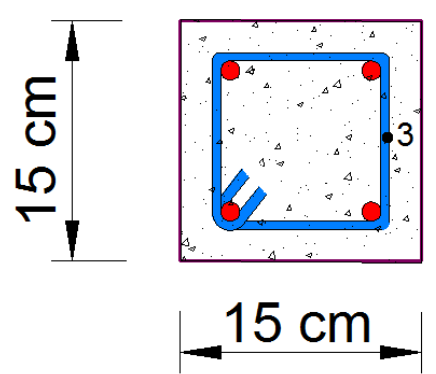
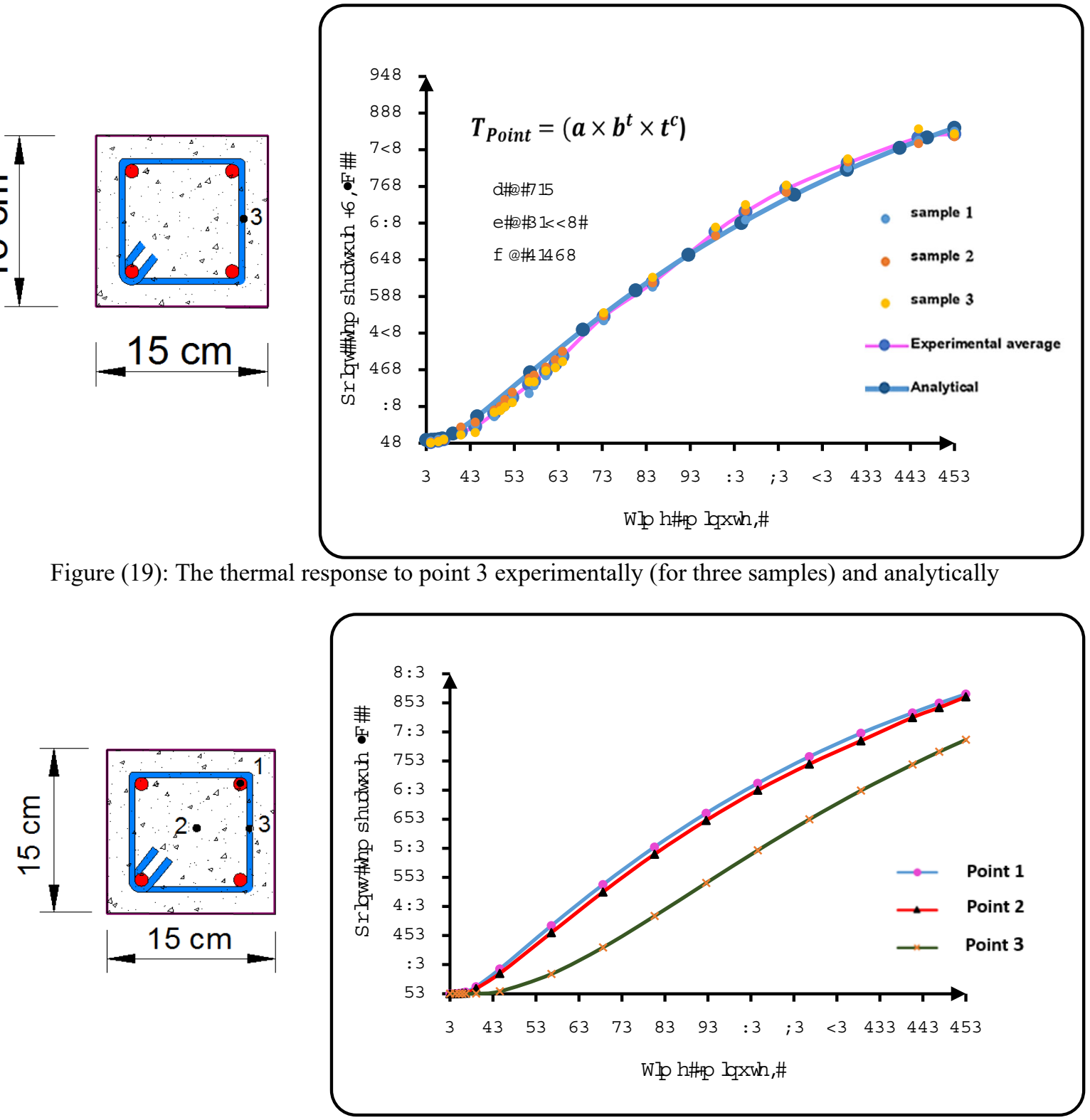

Figure (19): The thermal response to point 3 experimentally (for three samples) and analytically

Figure (20): The thermal response to the three points analytically

Figures $(21,22)$ show the thermal distribution of concrete , longitudinal and stirrups reinforcing steel using ANSYS Workbench program, and figure (23) shows the distribution of heat on the points located on the path (AB) and (CB) according to their distance from the surface. Orign2019 [6] describes the temperature change over time for the studied path. These relationships are included in Table (6).

D: Transient Thermal
Temperature
Type: Temperature
Unit: ${ }^{\circ} \mathrm{C}$
Time: 7200
\begin{tabular}{|l}
$\mathbf{5 8 1 . 0 8}$ Max \\
567.1 \\
553.11 \\
539.13 \\
525.14 \\
511.16 \\
497.17 \\
483.19 \\
469.2 \\
$\mathbf{4 5 5 . 2 2}$ Min
\end{tabular}
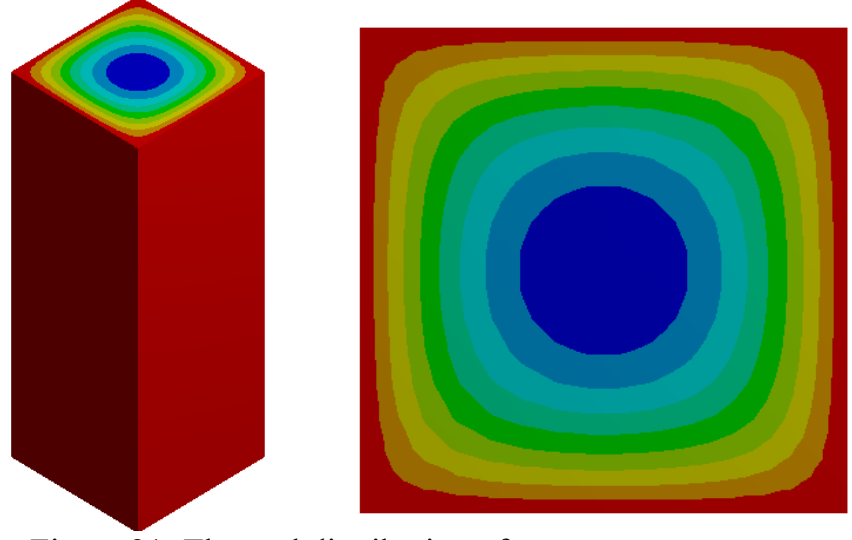

Figure 21: Thermal distribution of concrete 


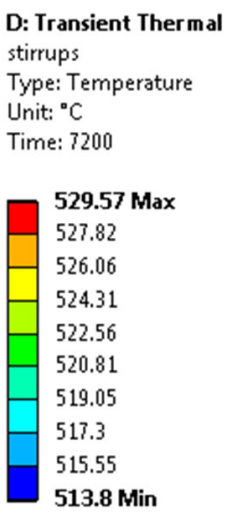

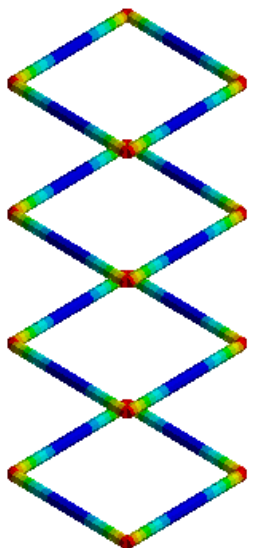

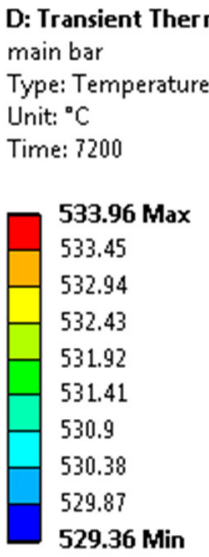

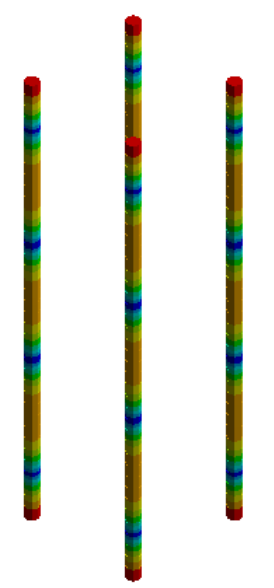

Figure 22: Thermal distribution in longitudinal and stirrups reinforcement steel
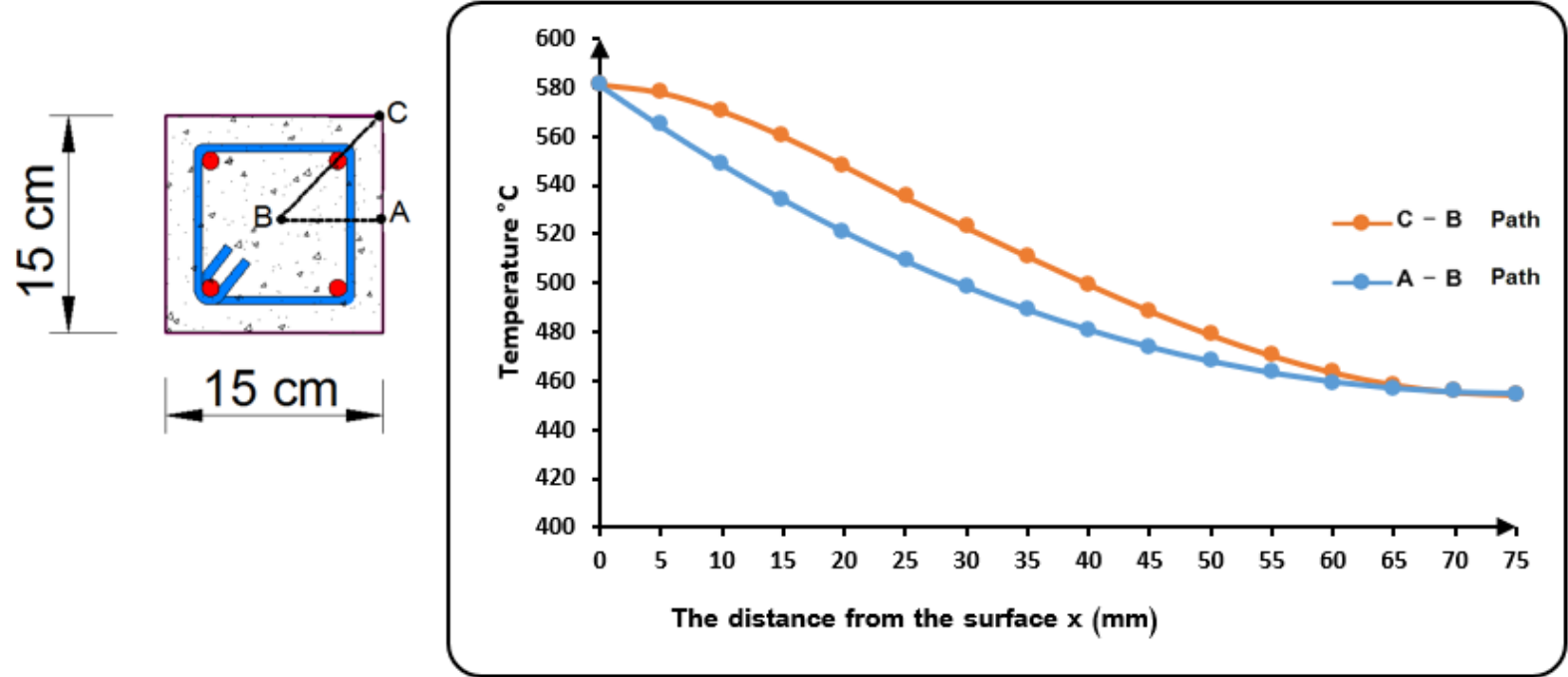

Figure (23): Heat distribution to the points located on the paths A-B; C-B

Table (6): Relationships expressing the heat distribution on paths A-B; C-B and its constants

\begin{tabular}{|l|c|c|c|}
\hline \multicolumn{1}{|c|}{ Relationships } & a & constants & c \\
\cline { 2 - 4 } & 581 & 227 & 1.14 \\
\hline Path C-B $\mathrm{T}_{\text {Point }}=\mathrm{a} /\left(1+\left(\frac{\mathrm{x}}{\mathrm{b}}\right)^{\mathrm{c}}\right)$ & 424 & -0.27 & 0.019 \\
\hline Path A-B $\mathrm{T}_{\text {Point }}=\mathrm{a} /\left(1+\mathrm{b} \times \mathrm{e}^{-\mathrm{c} \times \mathrm{x}}\right)$ & 427 & \\
\hline
\end{tabular}

\section{8- Results}

1- An analytical model has been found that accurately simulates the experimental model, and thus it is possible to dispense with doing experimental work and this leads to saving cost, effort and time.

2- The results of thermal analysis can be relied upon in estimating the failure load, and the design load of the structural element. Where the results of thermal analysis, give a clear visualization of the temperature distribution in the structural element, and thus calculate its carrying capacity according to the change of the properties of the materials, included in its composition with increasing temperatures, according to the proposed relationships. Thus, we can take the necessary precautions to protect the element from fire by using different methods of insulation, whether by using a special fire-resistant paint or by using, cement mortar

\section{9-Recommendations}

1- Increasing the number of thermocouples in the sample to determine temperatures in different places of the sample and compare the analytical results with the experimental results.

2- Testing the samples when exposed to a high temperature for 3-4 hours, and knowing the temperature that 
will be reached at the points $(1,2,3)$.

\section{References}

[2] ASTM E119.( 2001). "Standard Methods of Fire Endurance", American Society for Testing and Materials (ASTM)," USA,.

[6] program for graphing \& analysis vergion 19.

[7] S. Abrams M.(1971). "Compressive Strength of Concrete at Temperature to $1600^{\circ} \mathrm{F}, "$ American Concrete Institute (ACI) SP 25, Temperature and Concrete, Detroit, Michigan.

[8] M. Takla and I. Tarsha. (2019). "Determination of failure load for structural elements exposed to fire and comparison to the design load according to Isotherm500 method," Journal of Al Baath University, Homs,vol 41.

[9] ANSYS 12.(2008). "Finite element analysis system," SAS IP, Inc, USA.

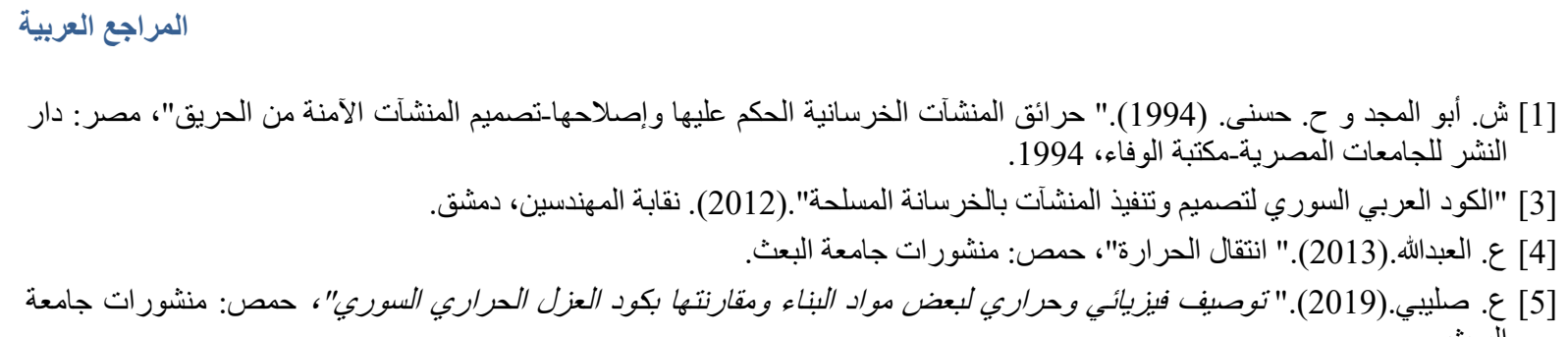

